\title{
PENGEMBANGAN KAWASAN AGROWISATA BERBASIS KOMODITAS UNGGULAN DI PAYO, SOLOK, SUMATERA BARAT
}

\author{
Rizka Amalia Nugrahapsari \\ Puslitbang Hortikultura Bogor \\ Email: nugra_hapsari@yahoo.co.id \\ Nur Qomariah Hayati \\ Puslitbang Hortikultura Bogor \\ Email: nur_qh@yahoo.com \\ Noor Roufiq Ahmadi \\ Puslitbang Hortikultura Bogor \\ Email: noorroufiqa@gmail.com \\ Idha Widi Arsanti \\ Pusat Pendidikan Pertanian \\ Email: idha_arsanti@yahoo.com \\ Hardiyanto \\ Puslitbang Hortikultura Bogor \\ Email: hardiyanto85@yahoo.com
}

\begin{abstract}
Solok City Government has a plan to develop area-based agrotourism in order to develop regional superior commodities. The research objectives are: (1) assessing the existing condition of agriculture and livestock, (2) assessing the role of stakeholder in developing Payo agro-tourism, (3) formulating Payo agro-tourism development strategies. The data used were primary and secondary data. Primary data were obtained from farmer interviews and participatory rural appraisal (PRA), as well as focus group discussions (FGD) with stakeholders. Data were analyzed with interactive analysis techniques and thematic analysis. The results showed that the socio-economic conditions of the community and the commitment of the local government supported the successful development of superior commodities in the Payo agro-tourism area. Potential and superior commodities based on land suitability, community and government interests are coffee, mangosteen, avocado, turmeric, chrysanthemum, and medicinal plants. But still needed support from IAARD
\end{abstract}


Rizka Amalia Nugrahapsari, Nur Qomariah Hayati, Noor Roufiq Ahmadi, Idha Widi Arsanti, Hardiyanto

technological innovation and institutional arrangement. The recommended steps in the development of Payo agro-tourism in a row are as follows: (1) structuring commodities according to land suitability, (2) providing technical guidance with methods that are easily understood, and (3) providing escort and institutional arrangement in developing agro-tourism areas. The involvement of IAARD in this effort can be started by drafting grand design of IAARD technological innovation support in Payo agro-tourism.

Keywords: agro-tourism, area, solok

\section{Pendahuluan}

Sejalan dengan rencana Pengembangan Nagari Mandiri Pangan, maka Pemerintah Kota Solok membuat rencana pengembangan kawasan pertanian sesuai dengan komoditi lokal. Mengacu kepada Peraturan Menteri Pertanian Republik Indonesia nomor 56/Permentan/RC.040/11/2016 tentang pengembangan kawasan pertanian, kawasan pertanian didefinisikan sebagai gabungan dari sentra sentra pertanian yang memenuhi batas minimal skala ekonomi pengusahaan dan efektivitas manajemen pembangunan wilayah serta terkait secara fungsional dalam hal potensi sumber daya alam, kondisi sosial budaya, faktor produksi dan keberadaan infrastruktur penunjang. Basuki (2012) menyatakan bahwa konsep dasar pengembangan kawasan agropolitan adalah menciptakan pembangunan interregional berimbang. Untuk mewujudkan pembangunan kawasan pertanian yang berkelanjutan, diperlukan perencanaan yang matang dengan strategi pengembangan yang berbasis masyarakat. Muslim (2007) menjelaskan bahwa kebijakan yang berbasiskan masyarakat akan menyebabkan masyarakat mempunyai rasa memiliki terhadap keputusan yang dibuat. Pembangunan kawasan agrowisata berbasis masyarakat dapat terwujud melalui upaya pelibatan masyarakat.

Penelitian yang mengkaji kawasan pertanian telah banyak dilakukan, antara lain dilakukan oleh Saptana et al. (2005) yang menyatakan bahwa pengembangan komoditas sayuran sebaiknya diarahkan pada daerah sentra produksi yang 
berdekatan dengan pusat konsumsi atau memiliki aksesibilitas yang baik ke daerah pusat konsumsi. Pengembangan kawasan juga perlu memperhatikan faktor kesesuaian lahan, aspek persepsi masyarakat, dan peningkatan kualitas sumberdaya manusia melalui kegiatan kelompok (Faizah dan Santoso, 2013; Krisnohadi dan Riduansyah, 2014; Ilsan et al. 2016). Namun penelitian yang mengkaji potensi Payo sebagai kawasan agrowisata belum ada yang melakukan.

Penelitian ini dilakukan untuk mengetahui potensi wilayah dan ekonomi, serta karakteristik sosial ekonomi pertanian masyarakat Payo dan sekitar Payo. Melesse (2018) menyatakan bahwa karakteristik sosial ekonomi dan tingkat keberanian masyarakat mengambil risiko akan menentukan tingkat adopsi teknologi. Adopsi teknologi juga dipengaruhi oleh faktor sumberdaya manusia, ekonomi, teknologi dan kelembagaan (Mwangi dan Kariuki 2015). Kajian ini diperlukan untuk menentukan tingkatan introduksi teknologi pada kegiatan "Dukungan Inovasi Teknologi Balitbangtan Dalam Pengembangan Kawasan Agrowisata Solok". Pambudi et al. (2018) menyatakan perlunya dukungan inovasi teknologi dalam pengembangan agrowisata.

Dukungan teknologi unggulan adalah pengimplementasian aspek teknis teknologi dan kelembagaan. Dari aspek teknis, seluruh inovasi teknologi diharapkan mampu meningkatkan kinerja pelaku agribisnis khususnya petani. Dari aspek kelembagaan, seluruh inovasi teknologi diharapkan dapat meningkatkan kinerja kelembagaan agribisnis yang selanjutnya berdampak pada peningkatan aksesibilitas petani terhadap pasar input dan output, serta permodalan. Peningkatan kinerja kedua aspek teknis dan kelembagaan agribisnis tersebut berikutnya diharapkan dapat berdampak positif pada kinerja hasil usahatani yang dicapai berupa peningkatan kesempatan kerja dan pendapatan. Tujuan penelitian adalah: (1) mengkaji kondisi eksisting pertanian dan peternakan, (2) mengkaji peran stakeholder dalam 
Rizka Amalia Nugrahapsari, Nur Qomariah Hayati, Noor Roufiq Ahmadi, Idha Widi Arsanti, Hardiyanto

pengembangan kawasan agrowisata Payo, (3) menyusun strategi pengembangan kawasan agrowisata Payo.

\section{Metode Penelitian}

Penelitian dilaksanakan pada tahun 2017 di kawasan Payo, Kelurahan Tanah Garam, Kecamatan Lubuk Sikarah, Kota Solok, Sumatera Barat. Pemilihan lokasi penelitian ditentukan secara sengaja berdasarkan hasil perencanaan pengembangan kawasan agro wisata pemerintah kota Solok.

Kajian ini menggunakan data primer dan sekunder. Data sekunder diperoleh dari data statistik pemerintah kota Solok, yaitu data jumlah penduduk berdasarkan usia. Data primer diperoleh dari wawancara petani secara mendalam (in depthinterview) menggunakan kuesioner dan observasi langsung. Wawancara dilakukan terhadap 30 petani di kawasan Payo dan 15 petani di sekitar Payo yang ditetapkan secara purposive dan snowball serta berdasarkan pengamatan lapang. Wawancara dilakukan di dua lokasi untuk menguji bahwa pemilihan lokasi di kawasan Payo lebih tepat dibandingkan di luar kawasan. Tujuan wawancara adalah untuk mendapatkan data karakteristik rumah tangga, pekerjaan utama dan sampingan penguasaan lahan, serapan tenaga kerja, pola tanam, keuntungan usahatani, penguasaan ternak, penerapan teknologi pertanian, curahan waktu kerja, pendapatan, konsumsi dan pengeluaran rumah tangga.

Data primer juga diperoleh melalui Participatory Rural Appraisal (PRA) dengan petani yang dipandu oleh moderator. Pendekatan dengan komunikasi kepada masyarakat merupakan strategi yang dipilih untuk melancarkan proses komunikasi sosialisasi program, penyusunan sampai tahap realisasinya (Miharja 2018). PRA merupakan metode yang tepat untuk mengidentifikasi potensi, permasalahan dan merumuskan alternatif solusi yang tepat secara partisipatif (Supriatna 2014) dengan cara melibatkan masyarakat dalam keseluruhan proses kegiatan mulai dari 
pengenalan kebutuhan, perencanaan, pelaksanaan, pemantauan sampai evaluasi (Departemen Kelautan dan Perikanan, 2006). Metode ini efektif untuk meminimalkan masalah yang muncul akibat ketidaksesuaian antara program pemerintah dengan program yang diinginkan masyarakat (Abdullah et al. 2012).

Selain itu juga dilakukan FGD dengan stakeholder yang dihadiri oleh walikota, wakil walikota dan Kepala OPD lingkup kota Solok Materi PRA dan FGD meliputi: (1) kondisi eksisting kawasan agrowisata kota Solok (potensi, masalah dan peluang pengembangan), (2) rencana kegiatan dukungan inovasi teknologi Balitbangtan dalam pengembangan kawasan agrowisata Kota Solok, (3) dukungan teknologi inovatif, (4) lokus penerapan rencana kegiatan dukungan, (5) keterlibatan instansi dan kelembagaan terkait, (6) delineasi tugas dan fungsi antar instansi, dan (7) pemanfaatan sumberdaya secara terarah dan terpadu.

Metode analisis data yang digunakan adalah teknik analisis interaktif (interactive model of analysis) dan teknik analisis tematik (thematic analysis). Miles dan Huberman (1984) menjelaskan bahwa teknik analisis interaktif memiliki tiga komponen yaitu reduksi data, sajian data dan penarikan kesimpulan. Reduksi data merupakan proses penyeleksian, pemfokusan, penyederhanaan dan abstraksi data lapang dalam kajian pengembangan kawasan agrowisata Payo. Penyajian data merupakan suatu pengorganisasian informasi berdasarkan klasifikasi dan kategori tertentu yang mengarah kepada penarikan kesimpulan pada kajian pengembangan kawasan agrowisata Payo. Penarikan kesimpulan merupakan pengorganisasian data dalam bentuk kesimpulan akhir. Analisis tematik digunakan untuk mengklasifikasikan tema dan subtema berdasarkan pada potensi, permasalahan dan peluang pengembangan agrowisata (Hayes, 1997 dalam Marwanti, 2015). 
Rizka Amalia Nugrahapsari, Nur Qomariah Hayati, Noor Roufiq Ahmadi, Idha Widi Arsanti, Hardiyanto

\section{Hasil dan Pembahasan}

\section{Karakteristik Rumah Tangga}

Masyarakat Payo memiliki rata rata umur tidak jauh berbeda dengan masyarakat di luar Payo. Kedua klaster tersebut didominasi oleh petani usia produktif, yaitu rata rata 45 tahun untuk kawasan Payo dan 48 tahun untuk luar kawasan. Sumberdaya tersebut merupakan potensi kuat untuk mendukung pengembangan kawasan agrowisata Payo. Hal yang perlu diperhatikan yaitu regenerasi petani dan metode diseminasi. Hal ini karena jumlah anggota keluarga yang bekerja di sektor pertanian rata rata 2 orang untuk setiap rumah tangga, yaitu orang tua saja, sedangkan anak anak bekerja di luar sektor pertanian dan masih sekolah.

Untuk mewujudkan kawasan agrowisata Payo yang berkelanjutan, maka dalam desain pengembangan perlu dirumuskan upaya menarik minat generasi muda untuk berpartisipasi dalam usahatani. Metode diseminasi juga menjadi faktor yang perlu diperhatikan karena rata rata petani memiliki tingkat pendidikan yang rendah yaitu tidak tamat SMP. Introduksi teknologi baru yang dilakukan harus menggunakan metode yang mudah dipahami dan mudah diterapkan, serta dalam menyampaikan informasi teknologi, penyuluh pertanian juga harus menggunakan bahasa yang sesuai dengan tingkat pendidikan petani. Hasil penelitian Burhansyah (2014) dan Obayelu et al. (2017) menunjukkan bahwa pendidikan merupakan salah satu faktor yang mempengaruhi adopsi teknologi.

Dalam hal ini peran penyuluh pertanian sangat penting, sebagaimana hasil penelitian (Tarukallo et al. 2014) yang menunjukkan bahwa penyuluh pertanian merupakan variabel yang berpengaruh nyata terhadap adopsi teknologi, dimana peningkatan adopsi teknologi dapat dilakukan melalui peningkatan frekuensi penyuluhan (Sumarno dan Hiola 2017; Wahyunindyawati et al. 2003) dan kualitas 
para penyuluh (Egwu 2015). Penyuluh pertanian dituntut untuk terlibat secara aktif dalam proses diseminasi baik melalui kunjungan lapang, praktek maupun demonstrasi plot (Nmadu et al. 2015). Penyuluh juga harus memperhatikan cara penyajian, strategi, metode dan pemilihan saluran komunikasi agar proses komunikasi dengan petani berjalan efektif. Karakteristik rumah tangga petani kawasan Payo dan luar kawasan Payo disajikan pada Tabel 1.

Tabel 1. Karakteristik Rumah Tangga Petani Kawasan Payo dan Luar Payo

\begin{tabular}{llcc}
\hline Keterangan & & Kawasan & Luar Kawasan \\
\hline Umur kepala keluarga (Tahun) & Rata- & 44,79 & 47,67 \\
& rata & & \\
& Min & 33,00 & 29,00 \\
& Max & 72,00 & 65,00 \\
Pendidikan kepala keluarga (Tahun) & Rata- & 7,13 & 8,78 \\
& rata & & \\
& Min & 2,00 & 6,00 \\
Jumlah anggota rumah tangga (orang) & Max & 12,00 & 12,00 \\
& Rata- & 4,50 & 4,78 \\
& rata & & \\
& Min & 2,00 & 2,00 \\
& Max & 9,00 & 7,00 \\
Jumlah anggota rumah tangga yang bekerja & Rata- & 1,74 & 1,67 \\
di pertanian & rata & & \\
& Min & 1,00 & 0,00 \\
& Max & 4,00 & 3,00 \\
\hline
\end{tabular}

Sumber: Peneliti (2020)

Secara umum, daya dukung pengembangan kawasan agrowisata Payo dari sisi sumberdaya manusia dapat terlihat pada Gambar 1. 
Rizka Amalia Nugrahapsari, Nur Qomariah Hayati, Noor Roufiq Ahmadi, Idha Widi Arsanti, Hardiyanto

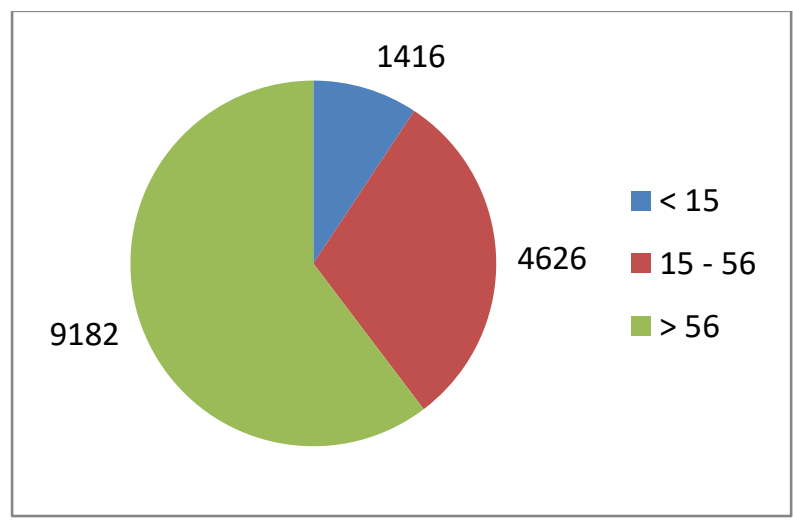

Gambar 1. Komposisi Jumlah Penduduk Berdasarkan Umur

di Kelurahan Tanah Garam

Sumber: Peneliti (2020)

Jumlah penduduk pada usia yang tidak produktif di Kelurahan Tanah Garam (9.182 orang) lebih banyak dibandingkan dengan jumlah penduduk usia produktif (4.626 orang). Oleh karena itu, kaderisasi penduduk usia $<15$ tahun untuk bekerja di sektor pertanian sangat penting. Jumlah penduduk usia $<15$ tahun juga menunjukkan seberapa besar komoditas tanaman hias mampu diserap oleh masyarakat Tanah Garam jika tanaman hias akan dijadikan salah satu komoditas yang dikembangkan. Penduduk pada usia tersebut berpotensi sebagai konsumen tanaman hias dalam bentuk penggunaan tanaman hias segar pada pesta pernikahan. Disamping itu, penduduk pada usia tersebut merupakan generasi muda yang menjadikan foto di sosial media sebagai bagian dari keseharian, sehingga tanaman hias di kawasan agrowisata Payo dapat dijadikan sebagai lokasi foto yang menarik.

Mayoritas petani di Payo memiliki pekerjaan utama sebagai petani (77,42\%). Sementara masyarakat di luar kawasan memiliki pekerjaan utama sebagai peternak $(22,22 \%)$, bekerja di warung, sopir, bengkel dan ojek (22,22\%). Hal ini menunjukkan bahwa masyarakat di luar kawasan Payo tidak mengandalkan sektor pertanian sebagai penopang perekonomian. Pemilihan Payo sebagai kawasan agrowisata merupakan keputusan yang tepat karena masyarakat sudah terbiasa bertani, sehingga 
introduksi teknologi relatif lebih mudah dilakukan dibandingkan dengan masyarakat di luar kawasan. Kondisi perekonomian masyarakat Payo yang menggantungkan hidup pada sektor pertanian dapat memudahkan petani menerima saran terkait perluasan skala usaha. Secara rinci, pekerjaan utama dan sampingan masyarakat kawasan Payo dan luar kawasan Payo disajikan pada Tabel 2.

Tabel 2. Pekerjaan Utama Masyarakat Kawasan Payo dan Luar Kawasan Payo

\begin{tabular}{lcc}
\hline Keterangan & Kawasan (\%) & Luar Kawasan (\%) \\
\hline Petani & 77,42 & 11,11 \\
Peternak & 6,45 & 22,22 \\
Buruh tani & 6,45 & 22,22 \\
Buruh nelayan & & 5,56 \\
Pengusaha dan pekerja bangunan & & 5,56 \\
Pedagang & 3,23 & 11,11 \\
Warung, sopir, bengkel dan ojek & & 22,22 \\
Lainnya & 6,45 & - \\
Jumlah & 100 & 100 \\
\hline
\end{tabular}

Sumber: Peneliti (2020)

\section{Kondisi Eksisting Pertanian dan Peternakan}

Sebagian besar lahan yang diusahakan petani adalah lahan kering, baik itu kawasan Payo maupun luar kawasan. Namun masyarakat Payo memanfaatkan lahan kering lebih banyak dibandingkan dengan luar kawasan, sebaliknya masyarakat luar kawasan lebih banyak memanfaatkan lahan sawah. Hal ini menunjukkan bahwa menetapkan kawasan Payo sebagai lokasi agrowisata merupakan pemilihan yang tepat karena pengembangan areal persawahan yang ada di luar Payo untuk menjadi kawasan agrowisata tidak mungkin dilakukan. Gambar 2 juga menunjukkan bahwa sebagian besar petani di kawasan Payo mengusahakan lahan kering milik sendiri. 
Rizka Amalia Nugrahapsari, Nur Qomariah Hayati, Noor Roufiq Ahmadi, Idha Widi Arsanti, Hardiyanto

Hanya sebagian kecil yang disakapkan kepada orang lain dan hanya sedikit juga yang menyakap lahan kering milik orang lain. Dengan pengusahaan lahan milik sendiri maka introduksi teknologi baru lebih mudah dilakukan karena petani dapat bertindak sebagai pengambil keputusan utama. Secara rinci, penguasaan Lahan Pertanian Kawasan Payo dan Luar Kawasan disajikan pada Gambar 2.

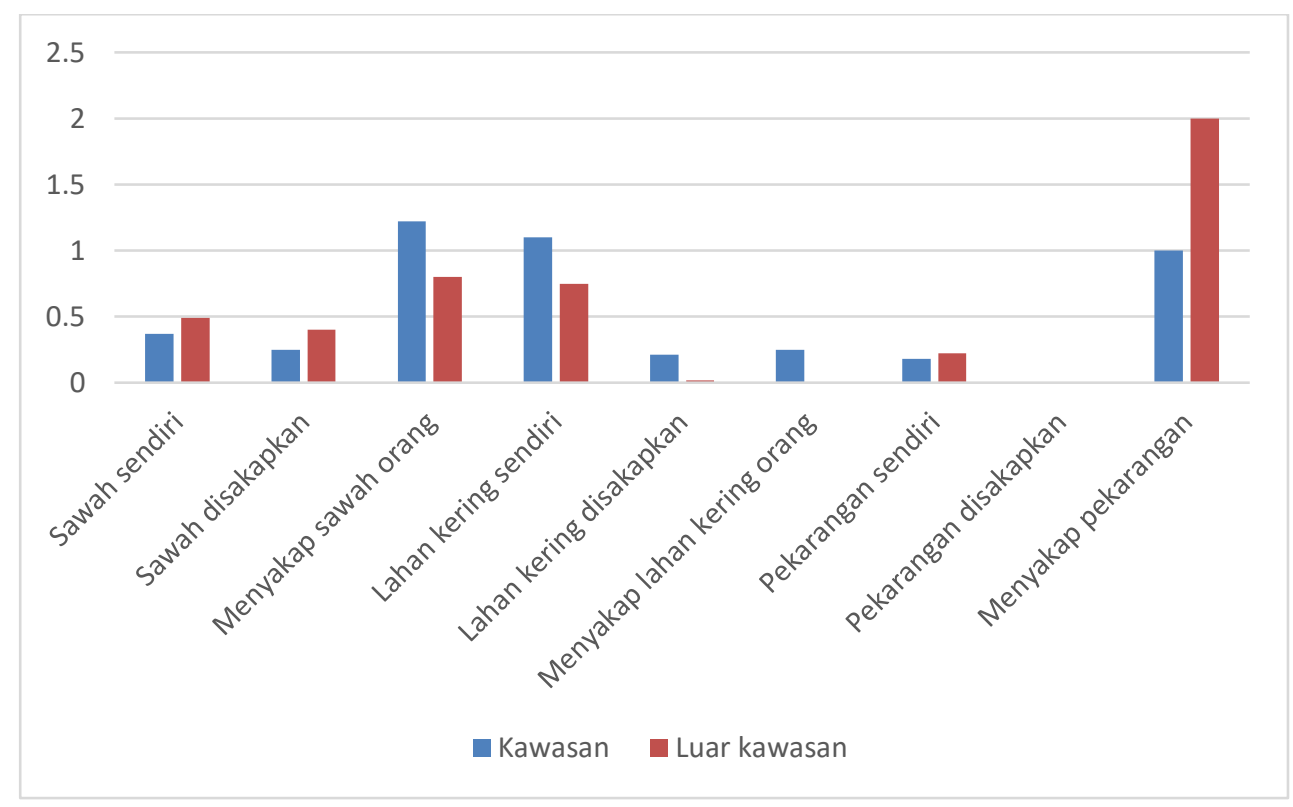

Gambar 2. Penguasaan Lahan Pertanian Kawasan Payo dan Luar Kawasan

Sumber: Peneliti (2020)

Sebagian besar petani Payo menggarap lahan sendiri, hal ini dapat dilihat dari tingginya serapan tenaga kerja rumah tangga pada lahan usaha milik sendiri, baik kepala keluarga maupun istri. Curahan waktu kerja yang besar di lahan milik sendiri ini dapat memudahkan keterlibatan petani dalam mendukung pembangunan kawasan agrowisata Payo. Sementara itu mata pencaharian petani di kawasan luar Payo sebagian besar buruh tani yang dapat dilihat dari besarnya serapan tenaga kerja petani yang bekerja di lahan milik orang lain. Hasil penelitian Howley et al. (2012) yang menunjukkan bahwa petani yang tidak memiliki pekerjaan di luar sektor pertanian akan mencurahkan waktu kerjanya lebih banyak di bidang pertanian dan 
memiliki peluang adopsi lebih besar. Secara rinci, serapan tenaga kerja rumah tangga dalam usahatani tahun 2016 di kawasan Payo dan luar kawasan Payo disajikan pada Tabel 3.

Tabel 3. Serapan Tenaga Kerja Rumah Tangga Tahun 2016 di Kawasan Payo dan Luar Kawasan Payo

\begin{tabular}{|c|c|c|c|c|c|c|c|}
\hline \multirow[b]{2}{*}{ Keterangan } & \multicolumn{3}{|c|}{ Musim hujan (HOK) } & \multicolumn{3}{|c|}{ Musim kemarau (HOK) } & \multirow{2}{*}{$\begin{array}{c}\text { TOTAL } \\
\text { (setahun) }\end{array}$} \\
\hline & $\begin{array}{l}\text { Lahan } \\
\text { sendiri }\end{array}$ & $\begin{array}{c}\text { Lahan orang } \\
\text { (upahan) }\end{array}$ & Total & $\begin{array}{l}\text { Lahan } \\
\text { sendiri }\end{array}$ & $\begin{array}{c}\text { Lahan orang } \\
\text { (upahan) }\end{array}$ & Total & \\
\hline \multicolumn{8}{|l|}{ Kawasan } \\
\hline Kepala keluarga & 23 & 8 & 31 & 3 & 3 & 6 & 49 \\
\hline Isteri & 6 & 3 & 19 & 0 & 1 & 1 & 20 \\
\hline \multicolumn{8}{|l|}{ Luar Kawasan } \\
\hline Kepala keluarga & 7 & 22 & 29 & 2 & 9 & 11 & 41 \\
\hline Isteri & 6 & 0 & 6 & 0 & 0 & 0 & 6 \\
\hline
\end{tabular}

Sumber: Peneliti (2020)

Komoditas yang ditanam oleh petani bervariasi. Komoditas utama yang diusahakan yaitu kunyit, kopi, jagung dan padi, sedangkan omoditas sampingannya yaitu pisang, cengkeh, kakao, serai, mangga, alpukat, pala dan jeruk. Komoditas yang dibudidayakan sejak dari zaman Belanda yaitu kopi, cengkeh, kemiri, kayu manis dan kakao. Komoditas tersebut telah berusia tua (kopi), namun kopi merupakan salah satu komoditas yang sebagian besar diusahakan masyarakat. Oleh karena itu komoditas utama yang diperbaiki dalam pembangunan kawasan agrowisata Payo adalah kopi. Hal ini sejalan dengan hasil penelitian Hariance et al. (2015) yang menunjukkan bahwa agribisnis perkebunan rakyat kopi robusta di Solok memiliki potensi untuk dikelola dan dikembangkan. Kunyit, serai dan jahe merupakan komoditas yang ditanam sejak krisis moneter. Komoditas yang diusahakan sejak era 70-an adalah bawang merah, cabai, kentang, kacang tanah, ubi kayu dan ubi jalar. Sayangnya masyarakat sudah 
Rizka Amalia Nugrahapsari, Nur Qomariah Hayati, Noor Roufiq Ahmadi, Idha Widi Arsanti, Hardiyanto

tidak banyak yang menanam komoditas tersebut karena harganya murah. Komoditas yang ditanam sejak 2 tahun terakhir yaitu mangga, alpukat, pepaya dan krisan.

Selain bertani, masyarakat kawasan Payo juga beternak, yaitu ayam dengan rata rata kepemilikan sebanyak 9 ekor per rumah tangga dan sapi sebanyak 5 ekor per rumah tangga. Disamping itu ditemukan juga pengusahaan ayam dan sapi dalam jumlah besar (20 ekor). Sapi dalam jumlah besar tersebut adalah bantuan dari pemerintah yang menjadi milik bersama. Hal ini menunjukkan bahwa petani kawasan Payo telah terbiasa beternak, sehingga integrated farming system (IFS) memungkinkan untuk diterapkan dari sisi dukungan dan kesiapan SDM. Namun perlu juga dilihat kesiapan faktor ketersediaan air, hijauan pakan ternak, sarana prasarana dan aspek pendukung lainnya. Hasil penelitian Soni et al. (2014), Kumara et al. (2017) dan Mamun et al. (2011) menunjukkan bahwa IFS dapat meningkatkan keuntungan petani, salah satu cara petani keluar dari kemiskinan, menjaga biodiversiti, menjaga kestabilan produksi melalui perbaikan sumberdaya alam, memenuhi kebutuhan konsumsi keluarga, sumber pupuk dan energi, serta mengatasi permasalahan ekologi. Secara rinci, gambar penguasaan ternak oleh petani kawasan Payo disajikan pada Gambar 3.

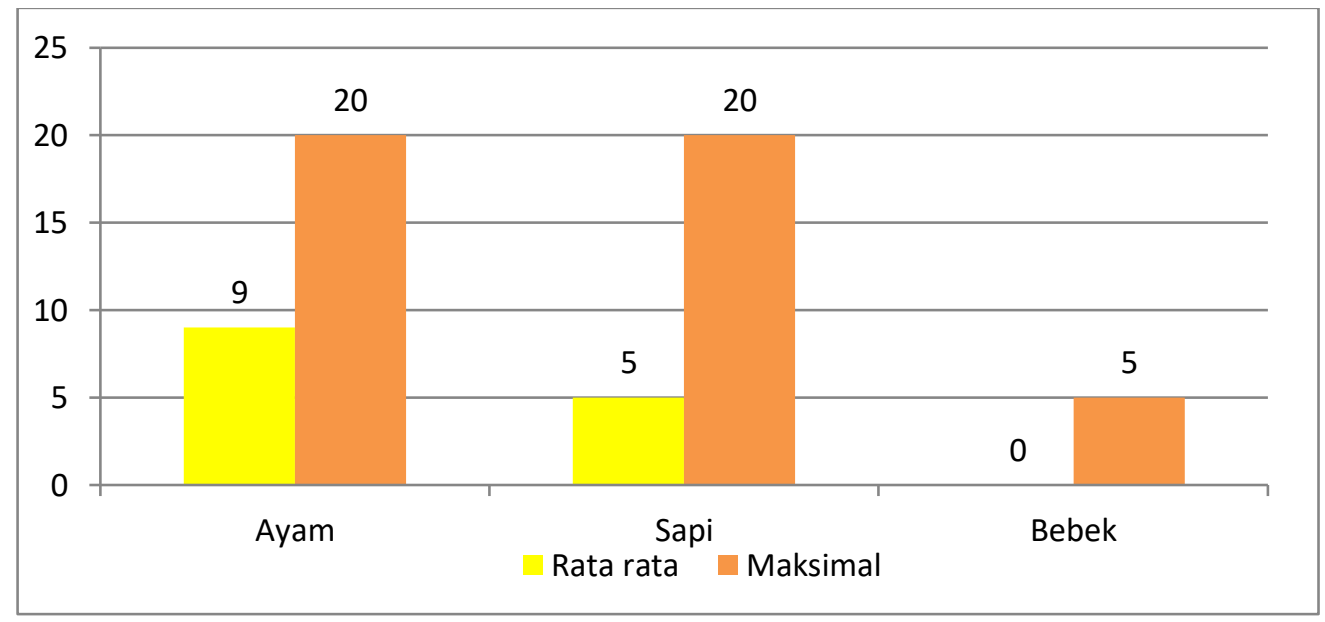

Gambar 3. Penguasaan Ternak Oleh Petani Kawasan Payo Sumber: Peneliti (2020) 


\section{Kondisi Eksisting Penerapan Teknologi Pertanian}

Tabel 4 menunjukkan penerapan teknologi pertanian oleh petani kawasan Payo, sedangkan Tabel 5 adalah untuk kawasan luar Payo. Perbedaan penerapan teknologi usahatani pada terdapat pada asal benih dan jarak tanam. Pada luar kawasan Payo terdapat petani yang mendapatkan bantuan bibit dari pemerintah, sedangkan untuk wilayah Payo bibit diperoleh dari hasil sendiri dan dari tetangga. Di luar kawasan Payo sudah ada petani yang menerapkan legowo, sedangkan untuk wilayah Payo belum menerapkan. Secara umum dapat dikatakan bahwa usahatani masyarakat masih bersifat tradisional. Selama ini penyuluh sudah melakukan pembinaan dengan baik, namun kelompok tani belum melakukan kegiatan sesuai dengan teknologi yang direkomendasikan karena tingkat pendidikan dan pemahaman yang rendah.

Tabel 4. Penerapan Teknologi Pertanian Petani Kawasan Payo

\begin{tabular}{|c|c|c|c|}
\hline Komponen teknologi & & Komoditas ${ }^{*}$ ) & \\
\hline Penanaman: & Padi & Kunyit & Kopi \\
\hline Sistem Tanam & Monokultur & $\begin{array}{l}\text { Monokultur dan } \\
\text { tumpangsari }\end{array}$ & $\begin{array}{c}\text { Tumpangsa } \\
\text { ri }\end{array}$ \\
\hline Pengolahan tanah & Intensif & Sederhana & Sederhana \\
\hline Penggunaan Benih (kg) & $10-20$ & $100-200$ & $50-150$ \\
\hline $\begin{array}{l}\text { Perlakuan seed treatment pada } \\
\text { benih }\end{array}$ & Ya & Sebagian ya & Tidak \\
\hline Asal benih yang digunakan & $\begin{array}{l}\text { Sendiri dan } \\
\text { tetangga }\end{array}$ & $\begin{array}{l}\text { Sendiri dan } \\
\text { tetangga }\end{array}$ & Tetangga \\
\hline Cara penanaman & $\begin{array}{c}\text { Sebar di } \\
\text { larikan, } \\
\text { pindah tanam }\end{array}$ & $\begin{array}{l}\text { Tugal, pindah } \\
\text { tanam }\end{array}$ & Tugal \\
\hline Jarak tanam & Teratur & Teratur & Teratur \\
\hline $\begin{array}{l}\text { Bila teratur, sebutkan jarak } \\
\text { tanam }\end{array}$ & $\begin{array}{l}20 \times 20 \mathrm{~cm} / \\
25 \times 25 \mathrm{~cm}\end{array}$ & $80 \times 40 \mathrm{~cm}$ & $300 \times 300 \mathrm{~cm}$ \\
\hline
\end{tabular}


Rizka Amalia Nugrahapsari, Nur Qomariah Hayati, Noor Roufiq Ahmadi, Idha Widi Arsanti, Hardiyanto

\begin{tabular}{|c|c|c|c|}
\hline Komponen teknologi & & Komoditas $^{*}$ ) & \\
\hline \multicolumn{4}{|l|}{ Pemeliharaan: } \\
\hline Frekuensi penyiangan & $1-2$ kali & 1-2 kali & 1 kali \\
\hline penyulaman & $\mathrm{Ya}$ & $\mathrm{Ya}$ & $\mathrm{Ya}$ \\
\hline $\begin{array}{l}\text { pengendalian } \\
\text { hama/penyakit }\end{array}$ & $\begin{array}{l}\text { Sebagian } \\
\text { melakukan }\end{array}$ & $\begin{array}{l}\text { Sebagian } \\
\text { melakukan }\end{array}$ & Melakukan \\
\hline $\begin{array}{l}\text { cara pengendalian } \\
\text { hama/penyakit }\end{array}$ & $\begin{array}{l}\text { Kimiawi, } \\
\text { nabati }\end{array}$ & Kimiawi & Kimiawi \\
\hline \multicolumn{4}{|l|}{ Pemupukan: } \\
\hline $\begin{array}{l}\text { pemupukan dasar sebelum } \\
\text { penanaman }\end{array}$ & $\begin{array}{l}\text { Sebagian } \\
\text { melakukan }\end{array}$ & Tidak melakukan & $\begin{array}{c}\text { Tidak } \\
\text { melakukan }\end{array}$ \\
\hline frekeunsi pemupukan & 1-2 kali & 1 kali & 1 kali \\
\hline $\begin{array}{l}\text { Dasar penetapan dosis } \\
\text { pupuk per hektar }\end{array}$ & $\begin{array}{l}\text { Sendiri dan } \\
\text { rekomendasi } \\
\text { PPL }\end{array}$ & Rekomendasi PPL & - \\
\hline Pemberian pupuk organik & $\begin{array}{l}\text { Sebagian } \\
\text { melakukan }\end{array}$ & Tidak melakukan & - \\
\hline \multicolumn{4}{|l|}{ Panen dan Pasca panen: } \\
\hline Cara perontokan & $\begin{array}{l}\text { Digebuk, } \\
\text { tresher }\end{array}$ & - & - \\
\hline Tempat perontokan & Di lahan & - & - \\
\hline Teknik pengeringan & $\begin{array}{l}\text { Dijemur } \\
\text { matahari }\end{array}$ & - & - \\
\hline Alas penjemuran & Plastik & - & Jalan aspal \\
\hline
\end{tabular}

*) komoditas utama masyarakat

Sumber: Peneliti (2020) 
Tabel 5. Penerapan Teknologi Pertanian Petani Luar Kawasan Payo

\begin{tabular}{|c|c|c|}
\hline \multirow{2}{*}{$\begin{array}{l}\text { Komponen Teknologi } \\
\text { Penanaman: }\end{array}$} & \multicolumn{2}{|c|}{ Komoditas *) } \\
\hline & Padi & Cengkeh \\
\hline Sistem Tanam & Monokultur & Monokultur \\
\hline Pengolahan tanah & Intensif & Sederhana \\
\hline Penggunaan Benih (kg) & $10-22,5$ & 100 \\
\hline $\begin{array}{l}\text { Perlakuan seed treatment pada } \\
\text { benih }\end{array}$ & Sebagian melakukan & Tidak melakukan \\
\hline $\begin{array}{l}\text { Asal benih/bibit yang } \\
\text { digunakan }\end{array}$ & $\begin{array}{c}\text { Hasil sendiri, } \\
\text { saudara/tetangga, bantuan } \\
\text { pemerintah }\end{array}$ & Hasil sendiri \\
\hline Cara penanaman & Pindah tanam & Sebar di larikan \\
\hline Jarak tanam & Teratur, legowo & Teratur \\
\hline Jarak tanam & $20 \times 20 \mathrm{~cm} / 25 \times 25 \mathrm{~cm}$ & $800 \times 800 \mathrm{~cm}$ \\
\hline \multicolumn{3}{|l|}{ Pemeliharaan tanaman: } \\
\hline Frekuensi penyiangan & 1-2 kali & 8 kali \\
\hline penyulaman & Melakukan & Melakukan \\
\hline pengendalian hama/penyakit & Sebagian melakukan & Melakukan \\
\hline $\begin{array}{l}\text { cara pengendalian } \\
\text { hama/penyakit }\end{array}$ & Kimiawi, nabati & Kimiawi \\
\hline \multicolumn{3}{|l|}{ Pemupukan: } \\
\hline $\begin{array}{l}\text { pemupukan dasar sebelum } \\
\text { penanaman }\end{array}$ & Sebagian melakukan & Melakukan \\
\hline frekeunsi pemupukan & $1-2$ kali & 1 kali \\
\hline $\begin{array}{l}\text { Dasar penetapan dosis pupuk } \\
\text { per hektar }\end{array}$ & Sendiri, rekomendasi PPL & Sendiri \\
\hline Pemberian pupuk organik & Sebagian memberikan & Memberikan \\
\hline \multicolumn{3}{|l|}{ Panen dan Pasca panen: } \\
\hline Cara perontokan & Digebuk, thresher manual & Digebuk \\
\hline Tempat perontokan & Di lahan & Di lahan \\
\hline Teknik pengeringan & Dijemur matahari & Dijemur matahari \\
\hline
\end{tabular}


Rizka Amalia Nugrahapsari, Nur Qomariah Hayati, Noor Roufiq Ahmadi, Idha Widi Arsanti, Hardiyanto

\begin{tabular}{llc}
\hline \multicolumn{1}{c}{ Komponen Teknologi } & \multicolumn{2}{c}{ Komoditas $\left.^{*}\right)$} \\
\hline $\begin{array}{l}\text { Alas penjemuran yang } \\
\text { digunakan }\end{array}$ & Plastik & Plastik \\
\hline
\end{tabular}

*) komoditas utama masyarakat

Sumber: Peneliti (2020)

\section{Curahan Waktu Kerja dan Pendapatan Rumah Tangga}

Untuk pekerjaan di bidang pertanian, petani di kawasan Payo memiliki jumlah hari kerja dan jam kerja lebih panjang, serta pendapatan lebih tinggi dibandingkan dengan petani di luar kawasan. Hal ini disebabkan sebagian besar petani di kawasan Payo menggarap lahan milik sendiri, sehingga petani memiliki komitmen untuk mencurahkan waktu kerja lebih banyak. Hal ini berarti bahwa usahatani merupakan sektor penopang perekonomian masyarakat. Komitmen masyarakat ini merupakan salah satu faktor pendukung rencana pengembangan kawasan agrowisata Payo. Secara rinci, curahan waktu kerja dan pendapatan rumah tangga petani di kawasan payo dan luar kawasan payo disajikan pada Tabel 6 .

Tabel 6. Curahan Waktu Kerja dan Pendapatan Rumah Tangga Petani di Kawasan Payo dan Luar Kawasan Payo di Sektor Pertanian

\begin{tabular}{lccc}
\hline \multicolumn{1}{c}{ Uraian } & Satuan & Nilai (Kawasan) & Nilai (Luar Kawasan) \\
\hline Pekerjaan pertanian: & & $2-27$ & \\
Jumlah hari kerja per bulan & HOK & $1-12$ & $2-20$ \\
Jumlah bulan per tahun & Bulan & $3-360$ & $8-12$ \\
Total hari kerja pertahun & Hari & $5-8$ & $24-300$ \\
Jam kerja perhari & Jam/hari & 1,5jt $-30 j \mathrm{jt}$ & $4-5$ \\
Pendapatan bersih per tahun & Rupiah & $1,8 j \mathrm{j}-25 \mathrm{jt}$ \\
\hline
\end{tabular}

Sumber: Peneliti (2020) 


\section{Kesesuaian Lahan}

Kawasan agrowisata Payo terletak di kelurahan Tanah Garam, Kecamatan Lubuk Sikarah, Kota Solok memiliki modal dasar keindahan alami yang dapat dikembangkan sebagai kawasan wisata agro dan perlu didukung oleh fasilitas infrastruktur yang memadai dan komoditas pertanian yang mempunyai nilai daya saing tinggi dan mampu meningkatkan taraf hidup masyarakat sekitarnya. Lokasinya mudah dijangkau dari Kota Solok dengan kendaraan roda-2 atau roda-4 selama +30 menit.

Kawasan Payo dan sekitarnya merupakan wilayah perbukitan dan pegunungan vulkanik tua, dengan ketinggian berkisar antara 400-1.200 m dpl, lereng sangat bervariasi dari landai sampai sangat curam $>40 \%$. Penataan lahan dengan sistem pertanian konservasi sangat dianjurkan agar tidak terjadi kerusakan lingkungan.

Hasil survei tim peneliti dari Balai Besar Sumber Daya Lahan Pertanian dalam laporan akhir kegiatan “Dukungan Inovasi Teknologi Balitbangtan dalam Pengembangan Kawasan Agrowisata Payo" Pusat Penelitian dan Pengembangan Hortikultura (2017) menyimpulkan bahwa:

1. Keadaan biofisik lahan dan iklim cukup mendukung keberhasilan pengembangan komoditas unggulan di kawasan agrowisata Payo dengan penerapan teknologi pengelolaan lahan yang tepat. Tanah umumnya bersolum tebal sampai sedang, tekstur halus, gembur, masam-agak masam serta iklim basah dengan curah hujan 2.000-2.500 mm/tahun dan suhu udara 25-27oC memberikan kondisi yang cukup sesuai untuk pengembangan berbagai komoditas pertanian di wilayah ini.

2. Hasil inventarisasi komoditas yang diusahakan oleh petani setempat terdapat 29 komoditas pertanian yang dievaluasi kesesuaiannya. Ke-29 komoditas 
Rizka Amalia Nugrahapsari, Nur Qomariah Hayati, Noor Roufiq Ahmadi, Idha Widi Arsanti, Hardiyanto

tersebut terdiri dari padi sawah, tanaman pangan lahan kering, tanaman sayuran, tanaman obat-obatan, tanaman hias, tanaman tahunan perkebunan dan buah-buahan serta tanaman tahunan bersifat konservasi (kemiri, bambu).

3. Berdasarkan hasil evaluasi kesesuaian lahan ternyata ke-29 komoditas tersebut dapat dikembangkan di wilayah ini dengan memilih lokasi yang sesuai dengan komoditasnya. Perlu menjadi catatan bahwa tanaman kopi dan kakao tergolong kelas sesuai marjinal di kawasan ini, artinya kesuburan tanah telah menurun sehingga peningkatan produktivitas lahan untuk kedua komoditas tersebut hanya dapat dicapai dengan pemberian input (pemupukan) yang cukup. Faktor pembatas utama pengembangan komoditas di wilayah ini adalah faktor retensi hara (kemasaman tanah, ketersediaan hara), kedalaman tanah dan faktor lereng/kemiringan lahan.

Berdasarkan baseline survey, minat masyarakat, dan dukungn Pemkot/Dinas terkait komoditas yang diunggulkan adalah tanaman kopi, manggis, alpukat, kunyit, tanaman hias (bunga Krisan), dan tanaman obat dan rempah (jahe, cengkeh, pala). Pada tahap awal sudah direncanakan Pengembangan komoditas tersebut lokasinya di plot dan disesuaikan dengan Peta Blok Arahan Komoditas Kawasan Agrowisata Payo skala 1:5.000.

\section{Peran Stakeholder Dalam Pengembangan Agrowisata Payo}

FGD dengan stakeholder menghasilkan kesepakatan peran stakeholder dalam pengembangan agrowisata Payo adalah sebagai berikut:

1. Usahatani yang dilakukan oleh masyarakat masih bersifat tradisional, namun masyarakat Payo bersifat terbuka dan mau menerima program pemerintah. Oleh kerana itu diperlukan bimbingan teknis dengan cara penyampaian yang mudah dipahami. Selain itu, pengembangan agrowisata Solok juga harus 
memperhatikan sosial budaya masyarakat, kelembagaan, pertanian yang terintegrasi dan kelestarian lingkungan.

2. Disamping sebagai kawasan agrowisata, Payo juga telah ditetapkan sebagai kawasan mandiri pangan melalui SK Gubernur Sumatera Barat No 521/206/DP. Untuk itu diperlukan dukungan inovasi teknologi Balitbangtan, khususnya dalam hal penyediaan varietas unggul, inovasi teknologi perbenihan, pendampingan berupa demplot, dan penyediaan narasumber.

3. Pemerintah daerah memiliki komitmen untuk membangun kawasan agrowisata Payo. Pemda memandang perlu adanya koordinator untuk percepatan kegiatan. Dalam hal ini Bapeda ditunjuk sebagai koordinator dengan dibantu oleh Asisten lainnya untuk mensinergikan langkah pembangunan agrowisata Solok dengan SKPD lainnya.

4. Implementasi grand design dukungan inovasi teknologi Balitbangtan dalam pengembangan agrowisata Solok perlu disinergikan dengan masterplan pembangunan kawasan agrowisata Kota Solok. Dalam hal ini, delineasi tugas antar stakeholder yang terlibat menjadi faktor kunci pelaksanaan.

5. Perlunya keterlibatan swasta dalam pengembangan agrowisata Payo untuk mempercepat proses pengembangan industri di kawasan tersebut.

\section{Strategi Pengembangan Agrowisata Payo}

Strategi pengembangan agrowisata Payo dapat dirumuskan sebagai berikut:

1. Dilakukan secara holistik melalui pendekatan rantai nilai dengan melibatkan berbagai stakeholder. Diharapkan pengembangan agrowisata Payo dapat memperluas pasar dengan memberikan insentif bagi investor swasta untuk melakukan investasi jangka panjang di bidang agribisnis pada komoditas terpilih. 
Rizka Amalia Nugrahapsari, Nur Qomariah Hayati, Noor Roufiq Ahmadi, Idha Widi Arsanti, Hardiyanto

2. Berdasarkan potensi daerah, kesesuaian lahan dan bersifat multi komoditas, serta berorientasi pada peningkatan pendapatan dan kesejahteraan masyarakat. Pendekatan ini diharapkan mampu mengakomodasi kepentingan pemerintah daerah, pelaku usaha, petani, dan stakeholder terkait, sehingga dapat berkelanjutan.

3. Didukung oleh inovasi teknologi Badan Penelitian dan Pengembangan Pertanian. Pemilihan dan penyampaian perlu mempertimbangkan aspek yaitu biofisik, karaktersitik petani, pelibatan instansi terkait, dan metode penyampaian (delivery system) teknologi. Informasi semua aspek tersebut perlu dirumuskan secara mendalam dalam bentuk grand desain inovasi teknologi Badan Penelitian dan Pengembangan Pertanian dalam agrowisata Payo.

\section{Kesimpulan dan Saran}

Kesimpulan dalam penelitian ini menunjukkan bahwa karakteristik masyarakat mendukung keberhasilan pembangunan kawasan agrowisata Payo. Petani masih didominasi oleh usia produktif dan masyarakat terbiasa bertani, sehingga introduksi teknologi lebih mudah dilakukan. Masyarakat Payo mayoritas menggantungkan hidup pada sektor pertanian dan menggarap lahan milik sendiri. Dengan pengusahaan lahan milik sendiri maka petani bersedia mencurahkan waktu kerjanya lebih banyak dan introduksi teknologi baru lebih mudah dilakukan.

Komoditas potensial dan diunggulkan berdasarkan minat masyarakat, dan dukungn Pemkot/Dinas terkait adalah tanaman kopi, manggis, alpukat, kunyit, tanaman hias (bunga Krisan), dan tanaman obat dan rempah (jahe, cengkeh, pala). Pengembangan komoditas unggulan tersebut perlu disinergikan dengan hasil survei kesesuaian lahan dan bersifat partisipatif (melibatkan petani sekitar). 
Pemerintah daerah dan stakeholder terkait memiliki komitmen dalam pembangunan agrowisata Payo. Namun penerapan teknologi pertanian masih bersifat tradisional, sehingga diperlukan dukungan inovasi teknologi Balitbangtan dalam pengembangan agrowisata Solok. Langkah langkah yang disarankan dalam pengembangan kawasan agrowisata Payo secara berturut turut adalah sebagai berikut: (1) penataan komoditas sesuai dengan kesesuaian lahan, (2) memberikan bimbingan teknis dengan metode yang mudah dipahami, dan (3) memberikan pengawalan dan penataan kelembagaan dalam pengembangan kawasan agrowisata. Keterlibatan Balitbangtan dalam upaya tersebut dapat diawali dengan pembuatan grand desain dukungan inovasi teknologi Balitbangtan dalam kawasan agrowisata Payo.

\section{Daftar Pustaka}

Abdullah MH, Rahamah N, Bakar A, Sulehan J, Awang AH, Liu O. 2012. Participatory Rural Appraisal (PRA): An Analysis of Experience in Darmareja Village, Sukabumi District,West Java, Indonesia. Akademika. 82 (1):15-19.

Basuki A. 2012. Pengembangan Kawasan Agropolitan. Jurnal Ekonomi dan Studi Pembangunan. 13(1):53-71.

Burhansyah R. 2014. Faktor Faktor yang Mempengaruhi Adopsi Inovasi Pertanian pada Gapoktan PUAP dan Non PUAP di Kalimantan Barat (Studi Kasus: Kabupaten Pontianak dan Landak). Informatika Pertanian. 23(1):65-74.

Departemen Kelautan dan Perikanan. 2006. Panduan Pengambilan Data Dengan Metode Rapid Rural Appraisal (PRA) dan Participatory Rural Appraisal.

Egwu E. 2015. Factors Affecting Farmer's Adoption of Agricultural Innovation in Delta State. Global Journal of Agricultural Economics, Extension and Rural Development. 3(2):177-182.

Faizah AA, Santoso E. 2013. Arahan Pengembangan Kawasan Pertanian Tanaman Pangan di Kabupaten Sampang. Jurnal Teknik Pomits. 2(2):197-199.

Hariance R, Febriamansyah R, Tanjung F. 2015. Agribisnis Perkebunan Rakyat Kopi Robusta di Kabupaten Solok. AGRISEP. 14(1):11-25. 
Rizka Amalia Nugrahapsari, Nur Qomariah Hayati, Noor Roufiq Ahmadi, Idha Widi Arsanti, Hardiyanto

Howley P, Donoghue CO, Heanue K. 2012. Factors Affecting Farmers' Adoption of Agricultural Innovations: A Panel Data Analysis of the Use of Artificial Insemination Among Dairy Farmers in Ireland. Journal Agricultural Science. 4(6):171-179.

Ilsan M, Nugroho AD, Efrinda, Winaryo, Handoyo R, Suparmono, Puspitasari R. 2016. Agribisnis Tanaman Hortikultura di Kabupaten Cilacap Provinsi Jawa Tengah. Agro Ekonomi. 27(2):233-252.

Krisnohadi AR. 2014. Analisis Pengembangan Kawasan Hortikultura Dengan Aplikasi Sistem Informasi Geografis dan Analytical Hierarchy Process. Jurnal Pedon Tropika. 1(1):37-47.

Kumara O, Sannathimmappa HG, Basavarajappa DN, Danaraddi VS, Pasha A, Rajani S. 2017. Integrated Farming System - An Approach Towards Livelihood Security, Resource Conservation and Sustainable Production for Small and Marginal Farmers. International Journal of Plant and Soil Science. 15(3):1-9.

Mamun SA, Nusrat F, Debi M. 2011. Integrated Farming System: Prospects in Bangladesh. Journal Environmental Science and Natural Resources. 4(2):127-136.

Marwanti S. 2015. Pengembangan Agrowisata Berbasis Masyarakat di Kabupaten Karanganyar'. Caraka Tani - Journal of Sustainable Agriculture. 30(2):48-55.

Melesse B. 2018. A Review an Factors Affecting Adoption of Agricultural New Technologies in Ethiopia. J Agri Sci Food Res. 9(3):1-4.

Miharja D. 2018. Strategi Komunikasi Dalam Rangka Peningkatan Ekonomi Keluarga (Studi Deskriptif Tentang Persepsi Warga dan Peranan Tokoh Masyarakat Dalam Program Mitra Pertanian Penggerak Pembangunan Desa (MP3D). Jurnal Agrimansion. 19(1):36-47.

Miles MB, Huberman A. 1984. Qualitative Data Analysis: A Sourcebook of New Methods, Sage Publication. London.

Muslim A. 2007. Pendekatan Partisipatif Dalam Pemberdayaan Masyarakat. Jurnal Aplikasi Ilmu-Ilmu Agama. 8(2):89-103.

Mwangi M, Kariuki S. 2015. Factors Determining Adoption of New Agricultural Technology by Smallholder Farmers in Developing Countries. Journal of Economics and Sustainable Developmen. 6 (5):208-217.

Nmadu JN, Sallawu H, Omojeso B. 2015, Socio-Economic Factors Affecting Adoption of Innovations By Cocoa Farmers in Ondo State, Nigeria. European Journal of Business, Economics and Accountancy. 3(2):58-66. 
Obayelu AE, Ajayi OD, Oluwalana EOA, Ogunmola O. 2017. What Does Literature Say About The Determinants of Adoption of Agricultural Technologies by Smallholders Farmers. Agricultural Research and Technology Open Access Journal. 6(1):1-5.

Pambudi SH, Sunarto, Setyono P. 2018. Strategi Pengembangan Agrowisata Dalam Mendukung Pembangunan Pertanian - Studi Kasus di Desa Wisata Kaligono (Dewi Kano) Kecamatan Kaligesing Kabupaten Purworejo. Analisis Kebijakan Pertanian, 16(2):165-184.

Pusat Penelitian dan Pengembangan Hortikultura. 2017. Laporan Akhir: Dukungan Inovasi Teknologi Balitbangtan Dalam Pengembangan Agrowisata Kota Solok Provinsi Sumatera Barat. Bogor.

Saptana, Ariningsih E, Dermoredjo SK, Darwis V. 2005. Kebijakan Pengembangan Hortikultura di Kawasan Agribisnis Hortikultura Sumatera (KAHS). Analisis Kebijakan Pertanian. 3(1):51-67.

Soni RP, Katoch M, Ladohia R. 2014. Integrated Farming System - A Review. Journal of Agricuture and Veterinary Science. 7(10):36-42.

Sumarno J, Hiola F. 2017. Faktor Sosial Ekonomi Yang Mempengaruhi Petani Mengadopsi Inovasi Pengelolaan Tanaman Terpadu Jagung di Gorontalo. Informatika Pertanian. 26 (2):99-110.

Supriatna A. 2014. Relevansi Metode Participatory Rural Appraisal Dalam Mendukung Implementasi Undang Undang Pemerintahan Desa. Widyaiswara Network Journal. 1(1):39-45.

Tarukallo PB; Unde AL. 2014. Faktor yang Mempengaruhi Adopsi Teknologi Biopestisida oleh Petani Sayur di Sendana dan Purangi Kota Palopo. Jurnal Komunikasi KAREBA. 3(2):125-132.

Wahyunindyawati; Kasijadi FH. 2003. Tingkat Adopsi Teknologi Usahatani Padi Lahan Sawah di Jawa Timur: Suatu Kajian Model Pengembangan Cooperative Farming. Jurnal Pengkajian dan Pengembangan Teknologi Pertanian. 6(1)40-49. 
Rizka Amalia Nugrahapsari, Nur Qomariah Hayati, Noor Roufiq Ahmadi, Idha Widi Arsanti, Hardiyanto

\section{Profil Penulis}

Rizka Amalia Nugrahapsari adalah Peneliti Ahli Pertama Pusat Penelitian dan Pengembangan Hortikultura. Menyelesaikan pendidikan program sarjana Fakultas Pertanian, Jurusan Sosial Ekonomi Pertanian, Program Studi Ekonomi Pertanian dan Sumberdaya, Institut Pertanian Bogor tahun 2006, Program Magister di Program Studi Agribisnis Institut Pertanian Bogor tahun 2013.

Nur Qomariah Hayati adalah Peneliti Ahli Muda Pusat Penelitian dan Pengembangan Hortikultura. Menyelesaikan pendidikan program sarjana Fakultas Pertanian Jurusan Sosial Ekonomi Pertanian Universitas Padjadjaran, Program Magister di Program Studi Agribisnis Institut Pertanian Bogor tahun 2013.

Noor Roufiq Ahmadi adalah peneliti ahli muda Pusat Penelitian dan Pengembangan Hortikultura. Menyelesaikan pendidikan program sarjana Fakultas Teknologi Pertanian Institut Pertanian Stiper Tahun 1998, Program Magister di Program Studi Ilmu dan Teknologi Pangan Universitas Gadjah Mada tahun 2004 dan program Doktor Program Studi Teknologi Industri Pertanian Institut Pertanian Bogor tahun 2012.

Idha Widi Arsanti adalah Kepala Pusat Pendidikan Pertanian Badan Penyuluhan dan Pengembangan Sumber Daya Manusia Pertanian (BPPSDMP) di lingkup Kementerian Pertanian. Mendapatkan gelar Sarjana Pertanian (jurusan agribisnis) pada tahun 1996 dari Institut Pertanian Bogor. Pendidikan S2 (Sosial Ekonomi dan Sumber Daya) di Universitas Gadjah Mada, Yogyakarta yang diselesaikan pada tahun 2002 dengan gelar Master Pertanian (MP). Pendidikan S3 doktoral (Ph.D) di bidang hortikultura ditempuh di Humboldt University, Berlin dan selesai pada tahun 2008. 
Hardiyanto adalah peneliti ahli madya di Balai Penelitian Tanaman Jeruk dan Buah Subtropika. Mendapatkan gelar sarjana pertanian (jurusan budidaya tanaman) pada tahun 1984 dari Universitas Brawijaya Malang. Pendidikan S2 (Seed Technology) di University of the Philippina, Los Banos (UPLB), Philipina dan selesai pada tahun 1994 dengan gelar Master of Science (M.Sc). Pendidikan S3 doktoral (Ph.D) dibidang hortikultura (crop Physiology / crop production and management) ditempuh di Universitas yang sama dan selesai pada tahun 2002. 